\title{
Gendered Infrastructural Citizenship: Shared Sanitation Facilities in Quarry Road West Informal Settlement, Durban, South Africa
}

\author{
Neele Wiltgen Georgi ${ }^{1}$ D $\cdot$ Sibongile Buthelezi ${ }^{2} \cdot$ Paula Meth $^{3,4} \mathbb{D}$
}

Accepted: 24 March 2021 / Published online: 10 July 2021

(C) The Author(s), under exclusive licence to Springer Nature B.V. 2021

\begin{abstract}
One significant component of the South African citizenship narrative is centred around the right to basic services and corresponding elements, including dignity and a healthy living environment. This paper employs the concept of infrastructural citizenship, which draws on both infrastructure and citizenship discourses to explore how participants experience and challenge public infrastructure and as such engage with questions surrounding citizenship on an everyday basis (Lemanski, 2019a). Adopting a gendered approach, this paper draws on the empirical case of Quarry Road West, an informal settlement located in Durban, and uses a qualitative methodology. Residents have access to Community Ablution Blocks, free shared sanitation facilities provided by the eThekwini Municipality. This paper argues that restricted access to the facilities undermines perceptions of privacy and health and negatively impacts women individually and in the community. Furthermore, this paper evaluates civic responses to inadequate infrastructure in the form of participation, protest and state-directed actions. As such, it examines how women-state relationships are embedded in public infrastructure, and limitations in regards to infrastructure shape interactions and engagements with the state, their experiences of citizenship, actualisation of rights and identities.
\end{abstract}

Keywords Gender · Community ablution blocks · Citizenship · Infrastructure · Informal settlements

\section{Introduction}

Citizenship is an inherently political relationship between a state and its citizens. In this context, it refers to a status conferred to a person, giving them the 'right to claim rights' from the state they belong to (Isin, 2012, p. 109). The political

Neele Wiltgen Georgi

neele.wiltgen-georgi@1stmed.ac.uk; n.wiltgengeorgi@gmail.com

Extended author information available on the last page of the article 
provision of equal citizenship to all South Africans in 1994 focused on an infrastructure-centric model of citizenship where delivering basic services to all citizens is seen as a critical strategy for reconciling inequalities, advancing positive urban transformation (Lemanski, 2019b). The rights to basic services, including water and adequate shelter, are embedded in the Constitution of the Republic of South Africa (1996) with the rights of access to basic water supply and basic sanitation required to guarantee sufficient water and an environment not harmful to health or well-being recognised under the 1997 Water Services Act.

Nevertheless, in spite of South Africa's progressive service delivery, inequalities within citizenship are manifested through the country's uneven infrastructure landscape, particularly in informal settlements where residents often struggle with absolute access to adequate shelter and basic services. Citizens respond in different ways. A fairly visible response is service delivery protests which have been common in South Africa throughout history. A prominent example gaining wide attention was the 2011 Toilet Wars where Cape Town informal settlement dwellers used a right-based discourse to pressure the state to provide for their sanitation needs (Redfield \& Robins, 2016). Adopting a range of tactics, including dumping human waste at Cape Town airport, they forced debates surrounding adequate sanitation delivery into the public eye and beyond their settlements (McFarlane \& Silver, 2017a). Activists made visible a fundamental everyday act, often considered a taboo subject, while highlighting the importance of sanitation for vulnerable groups disproportionately affected by inadequate infrastructure (Social Justice Coalition, 2013). Whilst sanitation access is a challenge that impacts on all informal settlement residents, some groups experience particular struggles in exercising their citizenship rights, with differences within these groups evident too, for example, due to age, gender or physical and mental abilities. Women, for example, experience unique sanitation challenges as they are required to fulfil socio-economic roles and address their bodily needs (Chant, 2013). Consequently, for women living informally, securing citizenship rights in relation to sanitation is particularly challenging.

While service delivery protests, including the 2011 Toilet Wars, illustrate that citizenship is embedded in a rights-based discourse, they also underline that citizenship is inherently a political relationship between the state and its citizens. Relationships between citizens and the state are manifested and conveyed through the materiality of, and access to, public infrastructure (Lemanski, 2019a). Lemanski (2020, p.2) devised the concept of infrastructural citizenship to draw on both infrastructure and citizenship discourses to understand 'the relationship between the physical and political nature of the state-society relations'. Adopting Lemanski's concept through a gendered perspective, this paper argues that by examining citizenship within gender and public infrastructure narratives, a specific lens on women-state relationships unfolds. The paper is concerned with how these relationships are embedded and mediated through public infrastructure and to understand the way women produce and encounter infrastructure and, as such, engage with questions of citizenship on an everyday basis. A gendered analysis is sensitive to difference but avoids assuming women experience sanitation or infrastructure entirely distinctly to men. Rather, the combination of women's bodily 
needs, socio-spatial relations, vulnerability and agency is examined here, recognising that sanitation is a significant challenge for men and women in informal settlements.

The paper uses Community Ablution Blocks (CABs) in Quarry Road West (QRW) as a case study to examine gendered infrastructural citizenship. The programme is administered by the eThekwini Municipality Water and Sanitation (EWS) unit, whose progress in service provision has been internationally recognised. In 2014, the unit received the Stockholm Water Industry Award for its transformative and inclusive approach to service provision (WSSCC, 2014). Nevertheless, despite considerable progress, questions remain regarding the quality of the services and impact on access, as discussed in this paper. Arguably, these limitations shape residents' interactions and engagements with the state, their experiences of citizenship, actualisation of rights and identities. Here, it is the gendered nature of this relationship that is under examination, and the paper uses the concept of infrastructural citizenship to move beyond viewing women purely as 'users' of services to examine the multiple relations and politics embedded within sanitation provision and the ways in which these are gendered.

This paper primarily focuses on sanitation. However, CABs are designed to address water, sanitation and hygiene (WASH) needs within the same facility, and sanitation cannot be explored without acknowledging and analysing water and hygiene access. Thus, these infrastructural elements are included where appropriate in this paper. The paper begins with an overview of debates on infrastructure and its relationship to the concept of citizenship, before advancing the call for using a gendered lens and exploring this within the South African context.

\section{Conceptualising Infrastructure}

The infrastructural turn in urban studies manifests a widespread conceptualisation of infrastructure to understand urban spaces (Lemanski, 2019a). This included a shift from a technical to a socio-economic and political understanding of infrastructure (Graham \& McFarlane, 2014). For example, Star (1999) defines infrastructure as both relational and ecological, reflecting its distinct meanings to different stakeholders. Furthermore, with their concept of people as infrastructure, Simone (2004) encourages a socio-economic interpretation of infrastructure, suggesting that urban dwellers create and recreate everyday urban life through relationships and practices appropriating available spaces and objects. More recently, Graham and McFarlane (2014) have highlighted how infrastructure is experienced and produced daily and is linked to the city's socio-economic and political dynamics. Focusing on infrastructure to conceptualise urban spaces, McFarlane (2019) highlights that sanitation, for example, is a networked rather than an isolated matter. Such networks are composed of different elements. Lawhon et al. (2018, p.720) propose the concept of heterogeneous infrastructure configurations to underline that infrastructure arrangements involve various 'technologies, relations, capacities and operations, entailing different risks and power relationships'. The multifaceted nature of infrastructure networks can lead to disruption, and while maintenance and repair are vital for infrastructure 
functioning, its disruption provides an opportunity for new solutions and debates, including incremental responses (Graham \& Thrift, 2007).

\section{Water and Sanitation Infrastructure in Urban South Africa}

South Africa's political history and infrastructure delivery are undeniably related. Unequal access to WASH infrastructure is linked to past policies of segregation and apartheid (Swanson, 1977). During apartheid, infrastructure was highly racialized, with non-white residents living in areas lacking infrastructure. The extent of inequalities and deficiencies varied depending on location, but Wilson and Ramphele (1989, p.130) identify resettlement and peri-urban areas, along with urban squatter settlements as all suffering from 'the chronic failure of local authorities to plan an appropriate infrastructure' with significant impacts on illness. Residents relied variously on overflowing and collapsing pit latrines, inadequate toilet pans with dire user ratios and drop pit lavatories (Wilson \& Ramphele, 1989). In contrast, areas reserved for the white population were generally well-serviced. These gross inequities in service delivery are a manifestation of unequal citizenship status, many of which remain present today, despite some significant improvements. Informal settlements, in particular, often experience limited access to sanitation infrastructure. In response to these inadequacies, different on-site and off-site sanitation technologies are used to meet sanitation needs, including ventilated improved pit latrines, urinediverting dry toilets or the $\mathrm{CAB}$ programme itself which consists of mobile and prefabricated containers providing WASH facilities to informal settlement communities (Gounden \& Alcock, 2017).

The post-apartheid South African citizenship discourse has a strong focus on providing infrastructure to all South African citizens, bridging past and current socioeconomic and political inequalities prevalent in the society (Lemanski, 2019b). The South African Constitution attributes the right to basic services (water and adequate housing) and interlinked elements such as human dignity to all citizens and remains the baseline for subsequent national and local legislations surrounding basic services such as the 1997 Water Services Act and the National Sanitation Policy (DWS, 2016). The mandate of provision is given to Water Service Authorities; in most circumstances, these are municipalities (Gounden \& Alcock, 2017). However, they often struggle to reduce service backlog and balance pro-poor and pro-growth agendas (Sutherland et al., 2014). For example, pro-poor agendas highlight the importance of participation in service provision. However, as is evident below, in reality, residents have limited involvement resulting in compromises tied to infrastructure. WASH infrastructure provision in South Africa is dynamic and continues to be varied. Responses to sanitation needs are observed at both the state and community or household level. Some informal settlements have benefitted from targeted improvements in sanitation services as the South African government positions itself as a developmental state and actively aims to improve sanitation provision. Gounden and Alcock (2017, p.2) reported that in 2014, 111,868 informal settlement dwellings in Durban were located within $200 \mathrm{~m}$ of Ablution Blocks. Nonetheless, interventions in informal settlements can be frustrated by their location on privately owned land, 
requiring permission from the landowner (Mels et al., 2009), and steep topography and overcrowding which leave little space for new engineering work (Gounden, 2008). Furthermore, increases in the urban population place growing pressure on these facilities yet arguably are often overlooked when facilities are planned (Mels et al., 2009).

At the household and community level, informal settlement residents often construct incremental infrastructure, infrastructure that is 'in-the-making, undergoing constant adjustment and intervention' (Silver, 2014, p.787). Water or sanitation systems are adapted to new pipes that redirect water to their houses and improve users' everyday lives (Silver, 2014). Community-led strategies include the politicisation of human waste, with McFarlane and Silver (2017a) outlining political tactics adopted by activists, residents and the state in informal settlements around Cape Town to negotiate the poor sanitation infrastructure. Tactics included the following: sanitation protests; audits on sanitation facilities supported by civil society organisations; sabotage of facilities such as vandalism to render these unusable and pressure for new ones, as well as blockages by the government who reason that they cannot provide services due to, for instance, reduced land availability (McFarlane \& Silver, 2017a). Through these activities, it is evident that public infrastructure, including sanitation facilities, represents a physical everyday citizenship engagement with the state (Rodina \& Harris, 2016). This argument is illustrated when analysing urban governance and citizenship in relation to sanitation infrastructure.

The varied involvement of residents, the state and other actors in infrastructure provision and use reveals that sanitation is seen differently by diverse actors articulated as seeing sanitation by McFarlane and Silver (2017b). The notion of seeing sanitation is based on Scott's, (1989) seeing like a state which reflects how the state aims to make society more legible and manageable. It also draws on Corbridge et al., (2005) concept of seeing the state, which analyses how urban dwellers see the state shaped by their informal and formal relationships and government expectations. Different ways of seeing sanitation point to clashes of expectations from different stakeholders. These are tied directly to differentiated ideas about citizenship rights and experiences. Citizenship can be understood as a legal fact actioned by the state, and it can also be understood as an everyday experience. As Isin (2008) highlights, citizenship is not only about the legal standing of individuals or institutions but also about the processes through which citizens engage and demonstrate their citizenship. According to Isin, (2012, p.10), citizenship acts refer to the ways citizens 'constitute themselves as political objects by the things they do, their deeds', such as voting. In contrast, citizenship practices can be understood as daily socialcultural and political ways to demonstrate these rights. Staehli et al. (2012) propose the concept of ordinary citizenship, highlighting that citizenship is more than a legal act and encompasses both legal forms and everyday practices. Thus, citizenship is fundamental to understanding everyday life. On a more radical note, Holston, (2009) coined the term insurgent citizenship to refer to radical citizenship actions where the urban poor, often perceived as second-class citizens, take collective disruptive actions to resist the state, challenge the status quo and make evident the validity of their claims. 
Promoting citizenship rights and infrastructure development are essential strategies of contemporary governments to achieve social-political and economic-technical progress, which is evident in South Africa, as discussed earlier. The concept of infrastructural citizenship, which draws on both citizenship and infrastructure literature, has been developed by Lemanski, (2019a, p.14) to analyse the "ways in which citizenship acts and practices are embodied in public infrastructure (and vice versa)'. In the same publication, McFarlane, (2019) positions sanitation infrastructure within the concept of infrastructural citizenship using the examples of Mumbai's Right to Pee Movement and Cape Town's Social Justice Coalition. This exemplifies two distinct forms of infrastructural citizenship where citizens politicise sanitation infrastructures, claiming rights from the state that are simultaneously of a material and political nature, such as the right to the city including active participation in civic life. While gender is introduced by both Lemanski, (2019a) and McFarlane, (2019), authors such as Datta and Ahmed, (2020), in an analysis of intimate infrastructures in Kerala, underline a lack of gendered focus when debating everyday infrastructure and rights claims. Our paper draws infrastructure, citizenship and gender narratives into conversation and argues that their interconnection reveals different ways women experience and negotiate their citizenship. In this case, this is based on gender disparities and sanitation.

\section{Gender Disparities and Sanitation}

Globally, informal settlements pose unique sanitation challenges for women in contexts where access to water supplies are often limited or costly and where the burden of accessing water is gendered. This is reinforced by women's cultural and socioeconomic roles (Chant, 2013). Moser's, (1993) triple role framework illustrates that women adopt reproductive roles such as childcare, productive roles including informal work that contributes to household income, and community roles such as voluntary maintenance of community facilities. In the practising of these roles, women are often at the forefront of inequalities tied to WASH infrastructure. Furthermore, most women also experience a range of biological and cultural processes, including menstruation, pregnancy, childbirth and menopause, demanding particular and gendered WASH infrastructure needs (Sweetman \& Medland, 2017). In addition, sociocultural norms surrounding hygiene, discretion and dignity shape how women use and engage with sanitation systems (Sweetman \& Medland, 2017). Nevertheless, even when other standards are met, including piped water and handwashing space, these infrastructural needs are rarely comprehensively considered nor satisfied in informal settings. Poorly planned shared WASH facilities also present gender-based violence (GBV) issues as services can be poorly lit and located far from the user's home (Gonsalves et al., 2015) or contribute to women's marginalisation, such as girls missing school as a result of not being able to manage their sanitation needs. These serve to reinforce gender-based inequalities (Sommer et al., 2015). These forms of violence can be conceptualised as a form of GBV understood by Rodgers and O'Neill (2012) as passive infrastructural violence, which refers to the negative implications of infrastructure policies or interventions on users. This violence 
is both on a physical and psychological level (Chaplin \& Kalita, 2017). It has also been noted by Datta and Ahmed, (2020), whose gendered approach to infrastructural violence identifies poor access to infrastructure as a form of intimate violence, noted earlier. This type of violence is perpetuated through numerous scales, modes, places and temporalities. As a response to issues of gender and sanitation, WaterAid highlighted in 2019 that the notion of adequate sanitation should be expanded to ensure that sanitation systems are 'safe and private, cater for menstrual and other hygiene management requirements, accessible to all, affordable and available when needed, well maintained and managed as well as meet the requirements of caregivers and parents' (Hueso et al., 2019, pp. 3-4). Furthermore, to make sanitation programs more efficient and sustainable, Carrard et al., (2013) propose a framework that accounts for multiple factors producing gender equality, including relationships and status, and which spans from the individual scale to the broader public area, underlining the complexity of gender in relation to sanitation infrastructure.

Returning to gender and citizenship, Lister (2012, p.372) underlines that 'citizenship has always been gendered in the sense that women and men have stood in a different relationship to it, to the disadvantage of women'. Gender, for example, is a significant factor in political participation and mediating relationships between state and citizens. Scorgie et al., (2016) suggest that more vigorous advocacy and participation of women at the community level are required to ensure that sanitation systems, especially shared ones, are responsive to female needs and meet local norms of dignity, safety and hygiene. Nevertheless, exploring civic activism regarding WASH services in Durban Mottiar et al., (2011) note that female-led organisations that adopt practices commonly deemed masculine, such as making use of plumbing skills to overcome water cut-offs due to non-payment, were considered 'successful' in achieving changes to their sanitation services. In contrast, activities attributed to a female-led organisation negatively impacted engagement at the local level and proposals regarding sanitation alterations were not implemented (Mottiar et al., 2011). These examples underline the need to recognise men and women may negotiate with local governments in different ways, suggesting governments may need to adopt alternative practices to learn how to engage, negotiate and understand women. Sultana (2020, p.14) argues that intersections produce different embodied subjectivities vis-a-vis the state, planners and urban elite', implying that the meaning of citizenship is different for each citizen and impacts how they go about negotiating their rights. As such, understanding women's lived experiences, how they create and live public infrastructure allows an insight into the ways women interact with citizenship issues. This paper proposes a gendered approach to infrastructural citizenship to examine how female citizenship acts and practices are expressed in relation to public infrastructure (and vice versa), drawing on shared sanitation facilities in Durban as a case study. This paper privileges a focus on gender, yet it recognises communities' overall struggle to access sanitation, including both men and women. It also recognises the significance of all forms of difference in shaping access to and experiences of sanitation. The LGBTQ+ community (Benjamin \& Hueso, 2017) and disabled people (Sommer et al., 2015) struggle with access to WASH facilities in particular ways. Although these challenges are not the focus of this paper, a 
feminist approach, alert to difference, is critical for a deepened understanding of the concept of infrastructural citizenship.

\section{Comments on Methodology}

This paper and its empirical work are informed by a feminist approach to understanding gender and urban processes. It privileges a focus on difference and specifically focuses on understanding the gendered dimensions when connecting infrastructure and citizenship narratives. The study targeted women for its analysis but recognised that a focus on masculinities, citizenship and infrastructure is a valid and understudied exercise in itself but is not the focus here. Part of a post-graduate student dissertation, the study underwent ethics approval by the University of Sheffield as administered by the Urban Studies and Planning Department.

The study adopted a qualitative approach focusing on a single case, namely, that of Quarry Road West, located in Durban. This case study was selected due to Buthelezi having extensive experience working in this area, the presence of CABs in this settlement and the settlement's relatively small scale. Buthelezi understands the complexities of the local context well and is well-known and trusted locally. Respondents were recruited through her and informed about the study's academic nature and its focus on gender. Respondents were assured of anonymity and were asked to provide written consent. This case study facilitated a detailed exploration of a specific infrastructure experience, the everyday use of CABs. In July 2019, 10 semi-structured interviews were conducted with female residents in QRW by Buthelezi. Participants were asked attitudinal questions detailing their everyday experiences of the facilities, how they met their gendered needs and their perceptions of the state. The women were between 18 and 64 years of age. They had different roles within the community, including that of a CAB caretaker. Their broader household compositions varied from one to six people, with eight of the ten women forming female-headed households. Additionally, the work draws on semi-structured interviews by Wiltgen Georgi with key informants from the eThekwini Municipality, the University of KwaZulu-Natal and the University of Sheffield. Key informants were recruited through the authors' networks. Their interviews focused on the history and specifics of sanitation infrastructure in Durban and the interpretations of trends evident in this case, alongside broader trends in urban infrastructure. All interviews were recorded, and the transcripts were analysed using a thematic analysis approach to highlight key similarities and differences while drawing theoretical conclusions across the data. The interviews with residents of QRW were conducted in isiZulu and translated into English by Buthelezi. No names of participants are used in this paper, instead participants are referred to by identification numbers (Participants ID). Meth supervised the dissertation project.

The research context under examination here is highly specific, and thus, findings from this study cannot be unquestioningly generalised. South Africans have unique citizenship rights embedded in the country's post-apartheid legislation. Furthermore, the data set is limited, and several of the findings are likely to align with male perceptions and their experiences of infrastructure that are not gender-specific. Nevertheless, this paper argues ultimately that the application of a gendered approach to 
the concept of infrastructural citizenship affords insights into specific women-state relationships, tied to women's embodied experiences of sanitation within a wider politics of infrastructure provision. Furthermore, infrastructural citizenship as a concept can itself be applied to other contexts, as Lemanski's, (2019a) work exemplifies. Acknowledging the importance of context also privileges the concept of situated knowledge, highlighting that knowledge is always produced in a particular context and is influenced by research stakeholders' identities.

\section{Discussion: Gendered Experiences of CABs in Quarry Road West and Their Relation to Citizenship}

\section{Context}

QRW is located in central Durban, a city where approximately $25 \%$ of the 3.75 million residents live in over 560 informal settlements (eThekwini Municipality, 2018, p.178). QRW has been settled for over 30 years, consists of approximately 1030 households and is divided into four sections (Sim et al., 2019). The land upon which QRW is located has multiple private and public owners, including the eThekwini Municipality and a private landlord (Sim et al., 2019). QRW is built on a 1:100-year floodplain straddling the Palmiet River, meaning it is considered a high-risk settlement and selected for relocation to state-sponsored housing (Mazeka et al., 2019). Indeed, in April 2019, the settlement suffered extensive flood-damage following significant flooding across Durban. QRW's status as a deferred relocation project directly influences the type of WASH infrastructure provided in the community (Williams et al., 2019). The settlement has been part of the iQhaza Lethu Partnership Project funded by the European Union, a participatory incremental upgrading programme with the aim to mobilise communities to participate in upgrading and to develop cross-sectoral partnerships to improve service delivery and living conditions in informal settlement communities (eThekwini Municipality, 2019, see also Sim et al., 2019). However, permanent in situ upgrading remains unlikely right now due to the hazardous location of the settlement.

QRW contains several CABs, which are prefabricated containers, modified to meet acceptable engineering standards by incorporating ventilation and plumbing and are free to use (Roma et al., 2010b). They exist in female and male blocks, providing toilets (urinals for men), showers, hand wash and laundry basins, and one block is designed to serve 100 housing units, but in reality, each often serves up to 200 households (where the average household counts on average '5.5 people') (Roma et al., 2010b, p. 2). Moreover, CABs should be within walking distance, approximately 150-200 m from the user's shelter (Gounden, 2008). The EWS also employs a community member as the caretaker who supervises facilities and reports any faults to the unit (Roma et al., 2010b). The CABs programme supports the Department of Health in enabling the prevention of diseases through related interventions. For example, the 2000 cholera outbreak in KwaZulu-Natal was another catalyst for providing safe free water to informal settlement residents (Sutherland et al., 2014), and bolstered by the recent COVID-19 pandemic. The ablution blocks 
also serve as a meeting place for community members and a central space for community notices to be pinned due to the likelihood that all members use the facilities daily (Sim et al., 2019).

\section{Different Ways of Seeing Infrastructure}

The participants of this study stated that they have access to CABs, but the facilities' access and use are undermined by low maintenance interlinked with challenges to women's privacy and dignity. Regarding low maintenance, the QRW 'facilities are broken and blocked all the time' (Respondent 9), and water pipes leak (Respondent 1). Shower walls were covered with mucus from users cleaning their noses, and toilets often remained unflushed (Respondents 2, 8, $9 \& 10$ ). The presence of doors without working locks increases women's fear of someone entering the bathroom, which impacts women's feelings of dignity, considered essential by Respondent 3 'because the toilet is a private thing'. Additionally, despite being issued separate blocks by the EWS, men and women are often forced to share facilities when the facilities reserved for female users are broken (Respondent 1). In these circumstances, women regarded sanitation facilities as hygienically unsafe:

'[We] have discovered that these facilities cause sickness to women. I have been in the clinic several times because of urine infection [...] My daughter [...] from Johannesburg used the facilities twice and became sick with the same infection. We are not safe using [these facilities] because we share the toilet with men.' (Respondent 9)

Furthermore, access to the facilities varies according to temporality. Some caretakers lock the facilities at night, and some women appeared afraid to use facilities during the night-time due to safety concerns, tied to fears of sexual violence:

'It is not safe to go there at night because it is dark and there is a rapist walking around at night. We feel not safe at night as women. Men's experiences are different because the men do not fear to go to the toilet at night while women fear to go alone.' (Respondent 12)

Women and men have different requirements regarding access to facilities. Women's sanitation needs cannot be easily scheduled and are subject to additional biological imperatives that can arise at any time, such as menstruation (Gonsalves et al., 2015). These realities impact achieving gender equality and dignity embedded in South Africa's Constitution. Existing infrastructure problems have repercussions for women regarding their everyday access to adequate and safe communal sanitation facilities. These serve to increase gendered inequalities and challenge their dignity, privacy and health. All of which can inhibit the realisation of rights and full citizenship. These negative consequences of policies are often unintended, and adverse outcomes cannot always be attributed to specific actors. Such passive outcomes are conceptualised by Rodger and O'Neill (2012, p.407) as passive infrastructural violence, which is distinct from active infrastructural violence, where there is the intentional physical exclusion of users, and relates 
rather to when the 'socially harmful effects derive from infrastructure's limitations and omissions rather than its direct consequences'. In QRW, increased fear of harassment and consequently restricted access to sanitation facilities at night is not a consequence intended by the EWS. Increased GBV is rather attributed to unequal gender relations and historical cultures of violence. Poor quality services similarly are a function of significant historical neglect and infrastructure failure. Such impacts directly affect the citizenship experience of women. Additional impacts on women's use and experiences of CABs include crowding around these facilities due to high user numbers. Above, we noted that CABs were servicing far more residents than planned. Low capacity of facilities increases the time burden for $\mathrm{CAB}$ users often a function of, and further entrenching the challenges of, gendered roles:

'[...] After you have finished washing you have to carry heavy washing to where you live. I have to fetch more than five buckets of water to bathe in the house. I hate doing laundry because I have to wait in the queue or wash in the house. That causes my back to become sore.' (Respondent 9)

Overcrowding and subsequent waiting to use the facilities may further undermine community social cohesion and reveal internal inequalities and power relations. Respondent 6 illustrated this:

'Some people end up fighting, but [the] quiet people are waiting [at] the washing place [and] have to wait until the queen [is] finished'.

This discourse of blaming others for the unavailability of facilities is prevalent and concerning. It includes accusing people with plumbing skills of stealing parts from the communal facilities (Respondent 6). Other participants accused the community more generally of not looking after the facilities, leaving them dirty and unusable for the next user (Respondent 8). Migrant residents from other African countries are blamed for creating 'a mess, because they do not value these facilities', evidencing potential xenophobic attitudes (Respondent 10). Therefore, limitations in infrastructure provision shape ideas of citizen-state relationship directly and can produce social tensions within the community.

State-citizen relations are shaped through the materiality and provision of everyday infrastructure. Most participants identified the municipality as the level of government responsible for providing sanitation services. Justifications included that the land belongs to the eThekwini Municipality (Respondent 1) and owing to the precedence of provision: 'they chose to start providing these facilities and must continue satisfying the community' (Respondent 3). The participants used clarification of their own roles to eschew practices of service provision: 'We are not here for building our own toilets'; instead, they emphasised that they are living in the settlement to search for employment and to financially support their families living elsewhere (Respondent 10). The participants emphasised the positive impact of municipal infrastructure revealing how the municipality is perceived through the materiality of infrastructure: 
'We do trust the municipality because there are so many things that the municipality has provided. It is a good indication that our municipality cares about the people.' (Respondent 4)

Some participants also recognised their responsibilities in maintaining the facilities and reporting any faults (Respondents $2 \& 4$ ).

The municipality situated itself as the developmental state, viewing sanitation as a 'constitutional mandate' (Municipality Representative, personal communication, 2019) in meeting the Department of Health's targets, including the prevention of diseases that might spread to city level. In short, their delivery has specific aims. For example, the EWS Customer Service Charter (2019, n.p.) sets out that its mission is 'to provide efficient, effective, affordable and sustainable water and sanitation services to the people of eThekwini in a customer-friendly manner'. Nevertheless, the EWS (2019) also outlines that users have responsibilities, including reporting leaks and illegal tampering to the municipality. In QRW, some participants were aware of these responsibilities, although some alleged that the government failed to respond consistently. These different perceptions of sanitation evidence that the relationship between state and citizen is conveyed differently through the infrastructure and is impacted by the everyday experience of the infrastructure. Some participants believe that the state cares about them, and most hold clear expectations regarding public infrastructure delivery. These expectations are, to some degree, recognised by the government and met through the provision of physical infrastructure. Although the gendering of these elements of the state-citizen relationship is not necessarily evident here, women's differential dependence on sanitation facilities mediates their overarching engagement with the state. Furthermore, respondents differ between themselves in how they enter into a dialogue with the state and clarify their expectations, navigating their relationship through an infrastructure. This becomes evident when looking at their workarounds to access sanitation.

\section{Women's Sanitation Workarounds: Invited Participation and Incremental Infrastructure}

When faced with inadequate infrastructure, the respondents reacted in different ways. Some sought active participation, aiming to draw attention to community matters and entering into a state-citizenship dialogue by participating in service delivery protests. Such protests are well documented across South Africa and highlight the state's difficulty fulfilling its infrastructure-centric vision of development and citizenship (McFarlane \& Silver, 2017a). Protests emerge for different reasons, including discontent, questions of development pace and issues of accountability and treatment of protesters (Mottiar \& Bond, 2012). Protesters adopt different tactics (Mottiar \& Bond, 2012), such as vandalism in this case. In QRW, some participants recalled protests for different services including housing, sanitation and electricity:

'We did protest regarding [the delivery of] toilets, and the municipality provides us [with new toilets]. We were using the plastic toilet, and the com- 
munity burned it. That time we walked to [Mwakondo 1] to use [their] toilet.' (Respondent 6)

Another example of active participation is residents who seek to be part of legitimised spaces of citizen participation, which Cornwall, (2002) refers to as invited spaces, including the ward committee. eThekwini Municipality is divided into wards with ward councillors representing the residents living in this area. QRW is located in Ward 23, currently a Democratic Alliance ward (Sim et al., 2019). Prior to the local government elections in 2016, it was an African National Congress ward with members of both political parties being part of formal governance structures. QRW residents are politically 'well organised' and have 'well established political structures' including an area committee that meets regularly and manages various responsibilities, including water, health and employment (Sim et al., 2019, p.8). QRW residents are represented on the local ward committee, a formal relationship between the local councillor and the broader community in Ward 23 and the eThekwini Municipality (Sim et al., 2019). The QRW community also has a strong working relationship with other institutions, including the University of KwaZulu-Natal, to identify their needs and negotiate with the government (see Sim et al., 2019). The two examples of active participation also display citizens' perceptions and relationship to the state because the residents yield and believe the state, with its power, will help-actively participating acknowledges this.

Participants are not always successful in establishing a dialogue. For example, protests may challenge the state and result in positive outcomes, but they can also disturb the infrastructure's everyday functioning (McFarlane \& Silver, 2017a). As a result of damages to sanitation infrastructure during protests, some residents of QRW had to utilise CABs in other areas of QRW, complicating their access further. Furthermore, while some participants were willing to be involved, in reality, formal structures to encourage meaningful and transformative participation are limited, undermining efforts to affect inclusion. Respondent 1 blamed the EWS for not involving the community, noting that they 'just install it without consulting us about what we need.' The feeling of not being able to participate in community decision compounds mistrust regarding the local ward committee, as concerns cannot be voiced (Respondents 1 \& 3). Moreover, wider changes in political governance work to restrict everyday participation in community structures. Respondent 8 stated:

'[The] old councillor was better than [the current] one because nothing has happened in this area and everything is quiet [since he has been elected]. If we call the community meeting, he is not coming and if we call him he's not answering the calls'.

Both ways of participation form dialogue between the women and the state. Challenging the government on service provision makes residents visible to the state and draws more comprehensive attention to inequalities experienced by women using infrastructure provision as a platform for this. The opportunity for women to participate in sanitation delivery is the ability to demonstrate and claim rights and engage in meaningful dialogue with the state. South African policies such as the National 
Sanitation Policy (DWS, 2016) underline the need to engage women in particular in consulting programmes and policy implementation. Participation is also crucial to achieving the acceptance and sustainability of sanitation systems (Roma et al., 2010a). A lack of dialogue between users and state means that the citizen-state relationship remains one-sided. The state may deliver infrastructure but is likely to ignore critical challenges the users face due to their inability to express these, resulting in further socio-economic marginalisation.

Not everyone seeks active participation due to a variety of reasons. Inconvenient timings of activities are critical. For example, Respondent 3, an elderly participant, explained she is 'not interested in any meeting [at night]'. Other respondents did not seem to be aware of any meetings happening or the opportunity to enter into a dialogue with the Municipality. Nevertheless, they produce and reuse infrastructure in the background to tend to their needs. One example is the illegal connection of water pipes. Respondent 5 stated that she was:

'tired [of] fetching water from far away, and [she] decided to [hire a] plumber.

[She] just bought the pipe, and he connected [it] from the tap to my house'.

Extending water services to the house reduces the physical and time burden as well as the risk of assault when fetching water at night or from afar. Such connections have also been observed by previous research conducted in QRW along with illegal connections of electricity wires (also known as izinyokanyoka) (Sim et al., 2019). In addition to altering existing infrastructure, female participants adopted a range of alternative solutions, most of which are gendered through their interconnections with women's bodily requirements, their domestic labour practices or their gendered vulnerabilities. Respondent 7 chose to bathe in her house because she perceived the showers as unclean, and Respondent 9 reported to use buckets to carry water to their house to wash themselves or their children. Other residents use buckets at night to relieve themselves due to fear of using the shared facilities in the dark. They carry the waste to the facilities early the next day (Respondent 2). Using buckets is a form of incremental infrastructure, evidencing Simone's, (2004) argument of humans as infrastructure. Here the physical labour (the carrying of water or human waste) performs the role of pipes.

Overall, several participants detailed the requirement and hope for additional facilities (Respondents 2, 8, $9 \& 10$ ). As such, the use of such alternatives is likely to continue as the sanitation backlog is significant. As of December 2017, the existing backlog of sanitation units across the city was about 138,570 units with a projected waiting period of 14-17 years (eThekwini Municipality, 2019). Through these practices, women become providers themselves and are less reliant on the state, shifting how they claim their citizenship rights and changing their relationship to the state. Nevertheless, the use of informal infrastructures or alternative methods to fulfil sanitation needs is paradoxical. On the one hand, creating informal structures fulfils participants' needs and instils illegal connections to claim their citizenship rights. On the other hand, incremental infrastructures simultaneously limit their citizenship experience. These connections can be destroyed if discovered by government actors and overall do not guarantee a sustainable solution. 


\section{State Responses to Inadequate Infrastructure}

The eThekwini Municipality recognises the issue of infrastructure maintenance, which can result in poor perceptions of the infrastructure and the state itself. The management component is crucial but difficult as there is no 'one size fits all approach', meaning that a maintenance system that works for one community does not necessarily work within other settlements (Municipality Representative, personal communication, 2019). Nevertheless, the state is working on new solutions to address significant backlogs. For example, it collaborates with the University of KwaZulu-Natal and the Bill and Melinda Gates Foundation on finding new innovative solutions to deliver sustainable infrastructure (Municipality Representative, personal communication, 2019). However, these solutions also have to account for broader social, economic and technical processes such as the residents' aspirations to own a home. Respondents 9, for example, associated inadequate communal facilities with this unfulfilled housing right.

'[The sanitation facilities] are very bad, we need proper houses. [...] people are not cleaning the area because they are staying in bad condition houses. They have to provide us with the proper houses. Once they change the houses, the current facilities would change. Our lives will change to stay in a clean and safe place.' (Respondent 9)

In other words, access to basic services does not equate to their notions of adequate housing, therefore impacting on their citizenship expectations. Constraints on the government's capacity to deliver reduces the feasibility of meeting this ideal and of enabling residents to be part of a modern infrastructural offer (Graham \& Marvin, 2001) with desires for constant connection to the existing infrastructure network. The municipality faces the 'dilemma to offer solutions that are economically and socially viable' (Municipality Representative, personal communication, 2019). The dilemma is reflected in eThekwini Municipality's (2011, para. 1) development policies which are both pro-poor and pro-growth, and its vision to 'Enjoy the reputation of being Africa's most liveable city, where all citizens live in harmony' by 2030. It hopes to achieve this vision through 'growing its economy' and 'meeting people's needs' (2011).

The progressive approach of the EWS is not to be overlooked. While the municipality provides incremental services, including CABs, this provision is affected by the status of QRW as a 'deferred relocation project' (Williams et al., 2019, p. 168). Despite its deferred settlement status, relocation of the settlement to government subsidy housing in the near future is unlikely. Being part of the iQhaza Lethu Partnership Project resulted in improvements to the settlement, including the incremental upgrading of services. Relocation would likely require movement to urban peripheries, a common location of state-subsidised housing as land is cheaper than centrally located land and therefore more economically viable for the government (Watson, 2009). Consequently, many QRW residents had refused relocations in 2009 and insisted on remaining at the settlement (Sim et al., 2019). As Respondent 9 stated: 
'QRW is near to the city, that is why [it is] easy for people who are looking for

a job or studying'.

Relocation to new housing can have adverse consequences impacting access to education and employment. Meth et al., (2019, p.1068) note that relocations to statesponsored housing settlements do not necessarily improve citizenship status, but often further marginalise residents, especially female beneficiaries. Infrastructure is a space where expectations from both state and citizen sides confront each other, and the relationship between both actors is shaped through this. The state recognises its duty to deliver basic sanitation needs to the citizens. However, it fails to meet everyone's needs. An improvement can be made through infrastructure provision on a smaller scale through, for example, incremental measures or on a larger scale through, for instance, through the provision of complete housing units. Nevertheless, the state also needs to balance this with meeting other aims such as economic development and navigating the expectations of different stakeholders to meet a certain level of provision that satisfies.

\section{Conclusions}

Adding citizenship to the gender and infrastructure narrative demonstrated how state-citizen relations are embedded and shaped through the materiality of everyday infrastructure. Drawing on shared sanitation infrastructure in Durban as a case study, this paper demonstrated this and further argued that restricted access and use of CABs limit women in exercising their full citizenship rights. Female participants often perceive sanitation facilities as unhygienic and not meeting their expectations of dignity, safety and privacy. Furthermore, facilities are often overcrowded, resulting in long waits and additional burdens to women who often have multiple roles at home and in the community. Arguably, the lack of planning of gendered needs restricts women in exercising their full citizenship rights. Participants adapt to inadequate access or the absence of WASH infrastructure by seeking active participation. Furthermore, they produce informal infrastructures to meet their sanitation needs or adopt other alternatives, including using the natural environment to manage their sanitary waste. This paper underlines that actors involved in the infrastructure provision see this in different ways. While participants complained about the state of the facilities, they are something that the state should continue to provide and improve. Correspondingly, the state recognises its constitutional mandate. The eThekwini Municipality funds and aims to provide the whole community with access to infrastructure while also employing a local caretaker to maintain the facilities. It presents itself as a developmental state, seeking to fulfil a specific mandate. However, the state's perception of users can limit their participation in decision-making processes, resulting in further marginalisation of the informal settlement dwellers and their needs.

These findings have informed the concept of infrastructural citizenship as they illustrate how female participants experience, produce and contest sanitation infrastructure and how this influences their citizenship identity, arguing women-state 
relations are embodied in and navigated through public infrastructure from both the state and citizen. Although caution is exercised around the generalisation of these empirical findings because of the study's small scale, a gendered lens could inform future research. This is not to ignore that the quality of infrastructure restricts access for men too, but to note the ways in which women's particular bodily realities, roles and vulnerabilities work to mediate their relationships with the state through sanitation provision.

Acknowledgements The authors are grateful to the residents of Quarry Road West for sharing their experiences with us, as well as key informants who agreed to be interviewed.

Data Availability Data available on request.

Code Availability Not applicable

Declarations

Competing Interests The authors declare no competing interests.

\section{References}

Benjamin, C. \& Hueso, A. (2017). Local action with international cooperation to improve and sustain water, sanitation and hygiene services LGBTI and sanitation: what we know and where the gaps are. Conference Paper for 40th WEDC International Conference, 24-28 July, 2017. https://wedc-knowl edge.lboro.ac.uk/resources/conference/40/Benjamin-2649.pdf Accessed 2 Sept 2019.

Carrard, N., Crawford, J., Halcrow, G., Rowland, C., \& Willetts, J. (2013). A framework for exploring gender equality outcomes from WASH programmes. Waterlines, 32(4), 315-333. https://doi.org/10. 3362/1756-3488.2013.033.

Chaplin, S. E. \& Kalita, R. (2017). Infrastructure, gender and violence women and slum sanitation inequalities in Delhi. CPR Research Report. New Delhi: Centre for Policy Research. Available from: https://www.cprindia.org/research/reports/infrastructure-gender-and-violence-women-andslum-sanitation-inequalities-delhi. Accessed 14 Mar 2021.

Chant, S. (2013). Cities through a "gender lens": a golden "urban age" for women in the global South? Environment and Urbanization, 25(1), 9-29. https://doi.org/10.1177/0956247813477809.

Corbridge, S., Williams, G., Srivastava, M. K., \& Véron, R. (2005). Seeing the state: governance and governmentality in India. Cambridge University Press.

Cornwall, A. (2002). Locating citizen participation. IDS Bulletin, 33, i-x. https://doi.org/10.1111/j.17595436.2002.tb00016.x.

Datta, A., \& Ahmed, N. (2020). Intimate infrastructures: the rubrics of gendered safety and urban violence in Kerala India. Geoforum, 110, 67-76. https://doi.org/10.1016/j.geoforum.2020.01.016.

Department of Water and Sanitation. (2016). National sanitation policy. Republic of South Africa. https://www. gov.za/sites/default/files/gcis_document/201706/national-sanitation-policy.pdf. Accessed 2 Sept 2019.

eThekwini Municipality. (2019). Integrated development plan 2018/2019. Resource Document. http:// www.durban.gov.za/City_Government/City_Vision/IDP/Documents/Forms/AllItems.aspx Accessed 2 Sept 2019.

eThekwini Municipality. (2018). Municipal spatial development framework 2018-2019. Resource Document. eThekwini Municipality. http://www.durban.gov.za/City_Services/development_planning_ management/Documents/SDF\%202018\%202019\%20MAY\%202018.pdf. Accessed 2 Sept 2019.

eThekwini Municipality. (2011). City vision. Online Resource. eThekwini Municipality. http://www.durban.gov.za/City_Government/CityVision/Pages/default.aspx. Accessed 2 Sept 2019. 
eThekwini Municipality Water and Sanitation Unit (EWS). (2019). eThekwini water and sanitation customer service charter. http://www.durban.gov.za/City_Services/water_sanitation/Customer_Service_ Charter/Documents/Customer\%20Service\%20Charter\%202018-2019.PDF. Accessed 5 Sept 2019.

Gonsalves, G. S., Kaplan, E. H., \& Paltiel, A. D. (2015). Reducing sexual violence by increasing the supply of toilets in Khayelitsha, South Africa: a mathematical model. PLoS One, 10, e0122244. https:// doi.org/10.1371/journal.pone.0122244.

Gounden T. (2008). Sustainable sanitation in the eThekwini Municipality. Presentation. Sustainable sanitation alliance. https:/www.susana.org/_resources/documents/default/2-790-pp10--t-gounden--susta inable-sanitation-in-ethekwini-mun-kompatibilitaetsmodus.pdf. Accessed 2 Sept 2019.

Gounden T. \& Alcock N. (2017). Sustainable FSM Services through integrated use of resources and innovative technologies: a case study of the eThekwini Municipality (Durban) South Africa. In I. Blackett, \& Hawk (Eds.), FSM innovation case studies - case studies on the business, policy and technology of faecal sludge management (2nd edition). Blackett, I. \& Hawkins, P. (eds). https:// www.susana.org/en/knowledge-hub/resources-and-publications/library/details/2760. Accessed 14 Mar 2021.

Graham, S., \& Marvin, S. (2001). Splintering urbanism. Routledge.

Graham, S., \& McFarlane, C. (2014). Infrastructural lives - urban infrastructure in context. Routledge.

Graham, S., \& Thrift, N. (2007). Out of order: understanding repair and maintenance. Theory, Culture \& Society, 24(3), 1-25. https://doi.org/10.1177/0263276407075954.

Holston, J. (2009). Insurgent citizenship in an area of the global urban peripheries. City \& Society, 21(2), 245-267. https://doi.org/10.1111/j.1548-744X.2009.01024.x.

Hueso, A., Beale, J., Stricker, J., Burgers, L., Nath, P., \& Drabble, S. (2019). Female-friendly public and community toilets: a guide for planners and decision makers. [Briefing note] Water Aid. https:// washmatters.wateraid.org/sites/g/files/jkxoof256/files/female-friendly-public-and-community-toile ts-briefing-note.pdf. Accessed 2 Sept 2019.

Isin, E. F. (2012). Enacting citizenship. In E. F. Isin (Ed.), Citizens without frontiers. (pp. 108-146). Bloomsbury.

Isin, E. F. (2008). Theorizing acts of citizenship. In E. F. Isin \& G. M. Nielsen (Eds.), Acts of citizenship. (pp. 15-43). Palgrave Macmillan.

Lawhon, M., Nilsson, D., Silver, J., Ernstson, H., \& Lwasa, S. (2018). Thinking through heterogeneous infrastructure configurations. Urban Studies, 55(2), 720-732. https://doi.org/10.1177/0042098017 720149.

Lemanski, C. (2020). Infrastructural citizenship: (de)constructing state-society relations. International Development Planning Review, 42(2), 115-125. https://doi.org/10.3828/idpr.2019.39.

Lemanski, C. (2019b). Introduction. In C. Lemanski (Ed.), Citizenship and infrastructure: practices and identities of citizens and the state. (pp. 1-7). Routledge.

Lemanski, C. (2019a). Infrastructural citizenship - spaces of living in Cape Town, South Africa. In C. Lemanski (Ed.), Citizenship and infrastructure: practices and identities of citizens and the state (pp. 9-21). Routledge.

Lister, R. (2012). Citizenship and gender. In K. Nash \& A. Scott (Eds.), The Wiley-Blackwell companion to political sociology (pp. 372-382). John Wiley and Sons.

Mazeka, B., Sutherland, C., Buthelezi, S., \& Khumalo, D. (2019). Community-based mapping methodology for climate change adaptation: a case study of Quarry Road West informal settlement, Durban, South Africa. In B. P. Cobbinah \& M. Addaney (Eds.), The Geography of Climate Change Adaptation in Urban Africa. (pp. 57-99). Palgrave McMillan.

McFarlane, C. (2019). The politics of urban sanitation: making claims to the city. In Lemanski C. (Ed.), Citizenship and infrastructure: practices and identities of citizens and the state (pp. 43-63). Routledge.

McFarlane, C., \& Silver, J. (2017). The Poolitical City: "seeing sanitation" and making the urban political in Cape Town. Antipode, 49, 125-148. https://doi.org/10.1111/anti.12264.

McFarlane, C., \& Silver, J. (2017). Seeing sanitation' and the urban political in an era of late neoliberalism. In T. Enright \& U. Rossi (Eds.), The urban political: the ambivalent spaces of late neoliberalism (pp. 123-143). Springer.

Mels, A., Castellano, D., Braadbaart, O., Veenstra, S., Dijkstra, I., Meulman, D., Singles, A., \& Wilsenach, J. (2009). Sanitation services for the informal settlements of Cape Town, South Africa. Desalination, 248, 330-337. https://doi.org/10.1016/j.desal.2008.05.072. 
Meth, P., Buthelezi, S., \& Rajasekhar, S. (2019). Gendered il/legalities of housing formalisation in India and South Africa'. Environment and Planning A: Economy and Space, 51(5), 1068-1088. https:// doi.org/10.1177/0308518X18792898.

Moser, C. O. (1993). Gender planning and development: theory, practice, and training. Routledge.

Mottiar, S., \& Bond, P. (2012). The politics of discontent and social protest in Durban. Politikon, 39(3), 309-330. https://doi.org/10.1080/02589346.2012.746183.

Mottiar, S., Naidoo, O., \& Khumalo, D. (2011). Women's organisations and the struggle for water and sanitation services in Chatsworth and Inanda, Durban: the Westcliff Flats Residents Association and the Didiyela Women's Group. Agenda, 25(2), 122-130. https://doi.org/10.1080/10130950.2011. 576005 .

Redfield, P., \& Robins, S. (2016). An index of waste: humanitarian design, "dignified living" and the politics of infrastructure in Cape Town. Anthropology Southern Africa, 39(2), 45-162. https://doi. org/10.1080/23323256.2016.1172942.

Rodgers, D., \& O'Neill, B. (2012). Infrastructural violence: introduction to the special issue. Ethnography, 13(4), 401-412. https://doi.org/10.1177/1466138111435738.

Rodina, L., \& Harris, L. (2016). Water Services, lived citizenship, and notions of the state in marginalised urban spaces: the case of Khayelitsha, South Africa. Water Alternatives, 9(2), 336-335.

Roma, E., Buckley, C., Jefferson, B., \& Jeffrey, P. (2010). Assessing user experiences of shared sanitation facilities. A case study of Community Ablution Blocks in Durban. South Africa. Water SA, 36(5), 589-594. https://doi.org/10.4314/wsa.v36i5.61992.

Roma, E., Buckley, C., Mbatha, S., Sibiya, L. \& Gounden, T. (2010b). Community ablution blocks with sewers or infiltration, eThekwini in Durban, South Africa - case study of sustainable sanitation projects. Online Resource. Sustainable Sanitation Alliance. https://www.susana.org/en/knowledge-hub/ resources-and-publications/case-studies/details/792. Accessed 28 Feb 2021.

Scorgie, F., Foster, J., Stadler, J., Phiri, T., Hoppenjans, L., Rees, H., \& Muller, N. (2016). "Bitten by shyness": menstrual hygiene management, sanitation, and the quest for privacy in South Africa. Medical Anthropology, 35(2), 161-176. https://doi.org/10.1080/01459740.2015.1094067.

Scott, J. (1989). Seeing like a state. Yale University Press.

Silver, J. (2014). Incremental infrastructures: material improvisation and social collaboration across postcolonial Accra. Urban Geography, 35(6), 788-804. https://doi.org/10.1080/02723638.2014.93360.

Sim, V., McCarthy, A., Sutherland, C., Buthelezi, S. \& Khumalo, D. (2019). Narratives of home and neighbourhood: possibilities for reimagining urban planning - exploring an in-situ upgrade: Quarry Road West informal settlement. Report University of KwaZulu-Natal in collaboration with the Durban Institute of Technology. https://narrativesofhome.org.za/wp-content/uploads/2019/08/Narra tives-of-Home-Quarry-Road-West.pdf. Accessed 28 Feb 2021.

Simone, A. (2004). People as Infrastructure: intersecting fragments in Johannesburg. Public Culture, 16(3), 407-429. https://doi.org/10.1215/08992363-16-3-407.

Sommer, M., Ferron, S., Cavill, S., \& House, S. (2015). Violence, gender and WASH: spurring action on a complex, under-documented and sensitive topic. Environment and Urbanization, 27(1), 105-116. https://doi.org/10.1177/0956247814564528.

Social Justice Coalition. (2013). Report of the khayelitsha 'mshengu' toilet social audit Report (pdf). http://sjc.org.za/wp-content/uploads/2018/09/social_audit_1_sjc_report_of_the_khayelitsha_mshen gu_toilet_social_audit.pdf. Accessed 2 Sept 2019.

Staeheli, L. A., Ehrkamp, P., Leitner, H., \& Nagel, C. R. (2012). Dreaming the ordinary: daily life and the complex geographies of citizenship. Progress in Human Geography, 36(5), 628-644. https://doi. org/10.1177/0309132511435001.

Star, S. L. (1999). The ethnography of infrastructure. American Behavioral Scientist, 43(3), 377-391. https://doi.org/10.1177/00027649921955326.

Sultana, F. (2020). Embodied intersectionalities of urban citizenship: water, infrastructure, and gender in the global south. Annals of the American Association of Geographers, 110(5), 1407-1424. https:// doi.org/10.1080/24694452.2020.1715193.

Sutherland, C., Hordijk, M., Lewis, B., Meyer, C., \& Buthelezi, C. (2014). Water and sanitation provision in eThekwini Municipality: a spatially differentiated approach. Environment and Urbanization, 26(2), 469-488. https://doi.org/10.1177/0956247814544871.

Swanson, M. (1977). The sanitation syndrome: Bubonic plague and urban native policy in the Cape colony, 1900-1909. The Journal of African History. 18(3), 387-410. http://www.jstor.org/stable/ 180639. Accessed 14 Mar 2021. 
Sweetman, C., \& Medland, L. (2017). Introduction: gender and water, sanitation and hygiene. Gender \& Development, 25(2), 153-166. https://doi.org/10.1080/13552074.2017.1349867.

The Republic of South Africa. (1997). Water services act, Act No. 108 of 1997. Policy Document. https:// www.gov.za/sites/default/files/gcis_document/201409/a108-97.pdf. Accessed 14 Mar 2021.

The Republic of South Africa (RSA). (1996). The Constitution of the Republic of South Africa, Act 108 of 1996. Policy Document. http://www.justice.gov.za/legislation/constitution/SAConstitution-web-eng. pdf. Accessed 28 Feb 2021.

Watson, V. (2009). 'The planned city sweeps the poor away.'.: urban planning and 21 st century urbanisation. Progress in Planning., 72, 151-193. https://doi.org/10.1016/j.progress.2009.06.002.

Water Supply and Sanitation Collaborative Council (WSSCC). (2014). "Most progressive water utility in Africa" wins 2014 Stockholm Industry Water Award. Online Blog. https://www.wsscc.org/2014/06/ 20/most-progressive-water-utility-in-africa-wins-2014-stockholm-industry-water-award/. Accessed 2 Sept 2019.

Williams, D. S., Máñez Costa, M., Sutherland, C., Celliers, L., \& Scheffran, J. (2019). Vulnerability of informal settlements in the context of rapid urbanization and climate change. Environment and Urbanization., 31(1), 157-176. https://doi.org/10.1177/0956247818819694.

Wilson, F., \& Ramphele, M. (1989). Uprooting poverty: the South African challenge. David Philip.

Publisher's Note Springer Nature remains neutral with regard to jurisdictional claims in published maps and institutional affiliations.

\section{Authors and Affiliations}

\section{Neele Wiltgen Georgi ${ }^{1}$ (D) $\cdot$ Sibongile Buthelezi ${ }^{2} \cdot$ Paula Meth $^{3,4}$ (CD}

Sibongile Buthelezi

buthelezib@ukzn.ac.za

Paula Meth

p.j.meth@sheffield.ac.uk

1 Department of International Public Health, Liverpool School of Tropical Medicine, Liverpool, UK

2 School of Built Environment and Development Studies, University of KwaZulu-Natal, Durban, South Africa

3 Department of Urban Studies and Planning, University of Sheffield, Sheffield, UK

4 School of Architecture and Planning, University of Witwatersrand, Johannesburg, South Africa 